\title{
Design and Maintainability Considerations Regarding the Effects of Suborbital Flights on Composite Constructed Vehicles
}

August 13, 2010

Eric C. Lundgren

Structures Department

Structural Mechanics Subdivision

Prepared for:

Volpe National Transportation Systems Center

U.S. Department of Transportation

Cambridge, MA 02142-1093

Contract No. DTRT57-05-D-30103, Task 27B

Authorized by: Space Systems Group

Public Release Is Authorized. 


\section{Design and Maintainability Considerations Regarding the Effects of Suborbital Flights on Composite Constructed Vehicles}

August 13, 2010

Eric C. Lundgren

Structures Department

Structural Mechanics Subdivision

Prepared for:

Volpe National Transportation Systems Center

U.S. Department of Transportation

Cambridge, MA 02142-1093

Contract No. DTRT57-05-D-30103, Task 27B

Authorized by: Space Systems Group

Public Release Is Authorized. 


\begin{tabular}{|c|c|c|c|c|c|c|c|}
\hline \multicolumn{7}{|c|}{ REPORT DOCUMENTATION PAGE } & $\begin{array}{c}\text { Form Approved } \\
\text { OMB No. 0704-0188 }\end{array}$ \\
\hline \multicolumn{8}{|c|}{$\begin{array}{l}\text { The public reporting burden for this collection of information is estimated to average } 1 \text { hour per response, including the time for } \\
\text { reviewing instructions, searching existing data sources, gathering and maintaining the data needed, and completing and reviewing the } \\
\text { collection of information. Send comments regarding this burden estimate or any other aspect of this collection of information, including } \\
\text { suggestions for reducing the burden, to the Department of Defense. Executive Services and Communications Directorate (0704-0188). } \\
\text { Respondents should be aware that notwithstanding any other provision of law, no person shall be subject to any penalty for failing to } \\
\text { comply with a collection of information if it does not display a currently valid OMP control number. } \\
\text { PLEASE DO NOT RETURN YOUR FORM TO THE ABOVE ORGANIZATION. }\end{array}$} \\
\hline \multicolumn{3}{|c|}{$\begin{array}{l}\text { 1. REPORT DATE (DD-MM-YYYY) } \\
13-08-2010\end{array}$} & $\begin{array}{l}\text { 2. REPOI } \\
\text { Contractor }\end{array}$ & $\begin{array}{l}\text { RT TYPE } \\
\text { Report }\end{array}$ & & \begin{tabular}{l|l} 
3. DATES \\
February 23 ,
\end{tabular} & $\begin{array}{l}\text { OVERED (FROM - TO) } \\
010-\text { July } 30,2010\end{array}$ \\
\hline \multirow{3}{*}{\multicolumn{5}{|c|}{$\begin{array}{l}\text { 4. TITLE AND SUBTITLE } \\
\text { DESIGN AND MAINTAINABILITY CONSIDERATIONS } \\
\text { REGARDING THE EFFECTS OF SUBORBITAL FLIGHTS } \\
\text { ON COMPOSITE CONSTRUCTED VEHICLES }\end{array}$}} & \multicolumn{3}{|c|}{\begin{tabular}{l|l} 
& February $23,2010-$ July 30,2010 \\
5A. CONTRACT NUMBER \\
DTRT57-05-D-30103
\end{tabular}} \\
\hline & & & & & \multicolumn{3}{|c|}{ 5B. GRANT NUMBER } \\
\hline & & & & & \multicolumn{3}{|c|}{ 5C. PROGRAM ELEMENT NUMBER } \\
\hline \multirow{3}{*}{\multicolumn{5}{|c|}{$\begin{array}{l}\text { 6. AUTHOR(S)* } \\
\text { E. C. Lundgren }\end{array}$}} & \multicolumn{3}{|c|}{$\begin{array}{l}\text { 5D. PROJECT NUMBER } \\
\text { FA } 88 \text { B2 HS998 }\end{array}$} \\
\hline & & & & & \multicolumn{3}{|c|}{$\begin{array}{l}\text { 5E. TASK NUMBER } \\
\text { Task Order } \# 27 \mathrm{~B}\end{array}$} \\
\hline & & & & & \multicolumn{3}{|c|}{$\begin{array}{l}\text { 5F. WORK UNIT NUMBER } \\
\text { FA88B2 HS998 }\end{array}$} \\
\hline \multicolumn{8}{|c|}{$\begin{array}{l}\text { 7. PERFORMING ORGANIZATION NAME(S) AND } \\
\text { ADDRESS(ES) } \\
\text { U.S. Department of Transportation } \\
\text { Research and Innovative Technology Administration } \\
\text { Volpe National Transportation Systems Center } \\
\text { Safety Information Systems Division } \\
\text { Cambridge, MA 02142-1093 }\end{array}$} \\
\hline \multirow{2}{*}{\multicolumn{6}{|c|}{$\begin{array}{l}\text { 9. SPONSORING/MONITORING AGENCY NAME(S) AND } \\
\text { ADDRESS(ES) } \\
\text { U.S. Department of Transportation } \\
\text { Federal Aviation Administration } \\
\text { Office of the Assoc. Administrator for Commercial Space Transportation } \\
\text { Washington, DC } 20591\end{array}$}} & \multicolumn{2}{|c|}{$\begin{array}{l}\text { 10. SPONSOR/MONITOR'S ACRONYM(S) } \\
\text { FAA AST-300 }\end{array}$} \\
\hline & & & & & & \multicolumn{2}{|c|}{ 11. SPONSOR/MONITOR'S REPORT NUMBER(S) } \\
\hline \multicolumn{8}{|c|}{$\begin{array}{l}\text { 12. DISTRIBUTION/AVAILABILITY STATEMENT } \\
\text { PUBLIC RELEASE IS AUTHORIZED }\end{array}$} \\
\hline \multicolumn{8}{|c|}{$\begin{array}{l}\text { 13. SUPPLEMENTARY NOTES } \\
\text { *The Aerospace Corporation, El Segundo, CA } 90245-469 \\
\text { DTRT57-05-D-30103, Task 27B }\end{array}$} \\
\hline \multicolumn{8}{|c|}{$\begin{array}{l}\text { 14. ABSTRACT } \\
\text { The Aerospace Corporation was tasked by the Volpe National Transportation Systems Center to provide technical support to the Federal Aviation } \\
\text { Administration, Office of Commercial Space Transportation (FAA/AST), in developing guidance for AST and industry use on operational limitations } \\
\text { and inspection requirements for suborbital reusable launch vehicles (RLVs) built using composite structures and subjected to a typical flight profile. } \\
\text { Four representative suborbital flight profiles were selected from a previous study. A review of the literature was conducted, which included peer- } \\
\text { reviewed journal articles, conference proceedings, and standards set forth by NASA, AIAA, and ASTM, with the goal of identifying the operational } \\
\text { environment phenomena, and their adverse effects on fiber-reinforced polymer matrix composites, and also considerations for maintenance of } \\
\text { composites, including lessons learned in the use of composites by the aviation community. Additional contributions were obtained from interviews } \\
\text { with various subject-matter experts at The Aerospace Corporation. Environmental phenomena, their adverse effects on composite structure, and } \\
\text { mitigation techniques, were identified. The phenomena were not ranked, in part due to lack of substantiated and uniform fidelity and maturity of data } \\
\text { for each, but also due to the potential for synergistic effects and for environment coupling. Additionally, further study and data are necessary to } \\
\text { understand the influence of exposure time on the effects of these phenomena, and also the severity of their effect at a representative suborbital } \\
\text { altitude. A substantial list of references is provided for further reading. }\end{array}$} \\
\hline \multicolumn{8}{|c|}{$\begin{array}{l}\text { 15. SUBJECT TERMS } \\
\text { Reusable Launch Vehicle, Suborbital, Composite Structures, Flight Environment, Lessons Learned, }\end{array}$} \\
\hline \multicolumn{4}{|c|}{ 16. SECURITY CLASSIFICATION OF: } & \multirow{3}{*}{\multicolumn{2}{|c|}{$\begin{array}{l}\text { 17. LIMITATION } \\
\text { OF ABSTRACT } \\
\text { UU }\end{array}$}} & \multirow{3}{*}{$\begin{array}{l}18 . \\
\text { NUMBER OF } \\
\text { PAGES } \\
23\end{array}$} & \\
\hline \multirow{2}{*}{$\begin{array}{l}\text { A. } \\
\text { REPORT } \\
\quad U\end{array}$} & \multirow{2}{*}{$\begin{array}{c}\text { B. ABSTRACT } \\
U\end{array}$} & \multirow{2}{*}{\multicolumn{2}{|c|}{$\begin{array}{c}\text { C. THIS PAGE } \\
\text { U }\end{array}$}} & & & & Ruth A. Hunter \\
\hline & & & & & & & $\begin{array}{l}\text { 19B. TELEPHONE NUMBER (INCLUDE } \\
\text { AREA CODE) } \\
\text { (617) } 494-2667\end{array}$ \\
\hline
\end{tabular}




\section{Design and Maintainability Considerations Regarding the Effects of Suborbital Flights on Composite Constructed Vehicles}

August 13, 2010

Eric C. Lundgren

Structures Department

Structural Mechanics Subdivision

Prepared for:

Volpe National Transportation Systems Center

U.S. Department of Transportation

Cambridge, MA 02142-1093

Contract No. DTRT57-05-D-30103, Task 27B

Authorized by: Space Systems Group

Public Release Is Authorized. 


\section{Design and Maintainability Considerations Regarding the Effects of Suborbital Flights on Composite Constructed Vehicles}

Approved by:

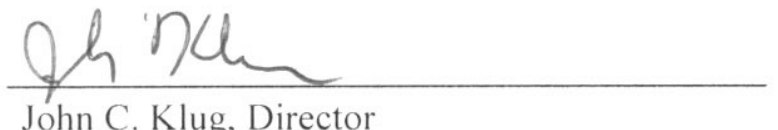

John C. Klug, Director

Structures Department

Structural Mechanics Subdivision

Vehicle Systems Division

Engineering and Technology Group

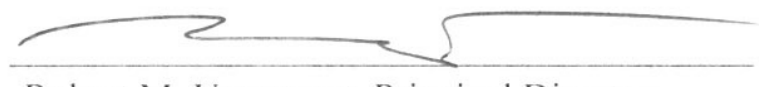

Robert M. Unverzagt, Principal Director

Civil and Commercial Launch Projects

Launch Systems Division

Space Systems Group 


\begin{abstract}
The Aerospace Corporation was tasked by the Volpe National Transportation Systems Center to provide technical support to the Federal Aviation Administration, Office of Commercial Space Transportation (FAA/AST), in developing guidance for AST and industry use on operational limitations and inspection requirements for suborbital reusable launch vehicles (RLVs) built using composite structures and subjected to a typical flight profile. Four representative suborbital flight profiles were selected from a previous study. A review of the literature was conducted, which included peer-reviewed journal articles, conference proceedings, and standards set forth by NASA, AIAA, and ASTM, with the goal of identifying the operational environment phenomena, and their adverse effects on fiber-reinforced polymer matrix composites, and also considerations for maintenance of composites, including lessons learned in the use of composites by the aviation community. Additional contributions were obtained from interviews with various subject-matter experts at The Aerospace Corporation. Environmental phenomena, their adverse effects on composite structure, and mitigation techniques, were identified. The phenomena were not ranked, in part due to lack of substantiated and uniform fidelity and maturity of data for each, but also due to the potential for synergistic effects and for environment coupling. Additionally, further study and data are necessary to understand the influence of exposure time on the effects of these phenomena, and also the severity of their effect at a representative suborbital altitude. A substantial list of references is provided for further reading.
\end{abstract}




\section{Acknowledgments}

The author wishes to thank Dr. Oscar Esquivel, for graciously agreeing to contribute to the area of non-destructive testing, and Dr. Thomas W. Giants, Ms. Maben Jimenez, Dr. Howard A. Katzman, Dr. John C. Klug, Dr. James P. Nokes, Dr. Ernest R. Scheyhing, and Dr. Natverlal R. Patel, all aforementioned of The Aerospace Corporation, for providing valuable technical input and guidance, and Mr. Robert W. Seibold, who served as the Aerospace program manager. Gratitude is extended to Mr. Jesse Hanson and Mr. Mahamane Touré at the Office of the Associate Administrator for Commercial Space Transportation, Federal Aviation Administration, and to Ms. Ruth A. Hunter, the Contracting Officer's Technical Representative (COTR) at the Volpe National Transportation Systems Center, for their valuable guidance and support. 


\section{Contents}

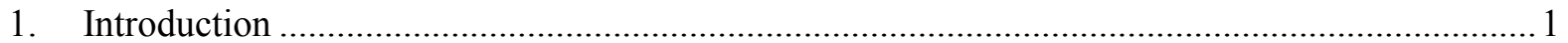

2. Candidate RLV Concepts and Composite Construction............................................................... 3

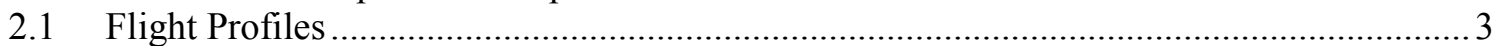

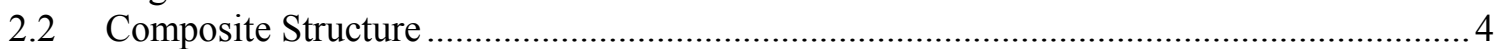

3. Operational Environments and Their Effects on Composites ................................................. 5

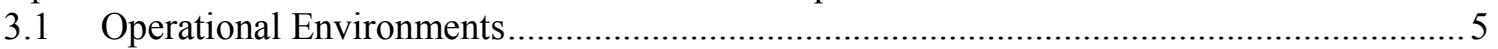

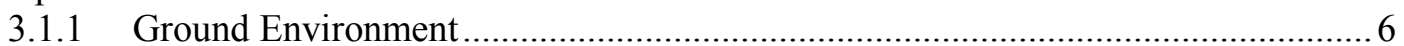

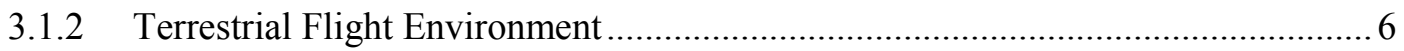

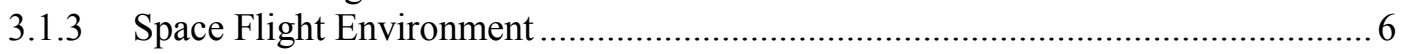

3.2 Environmental Phenomena and Their Effects on Composites ......................................... 7

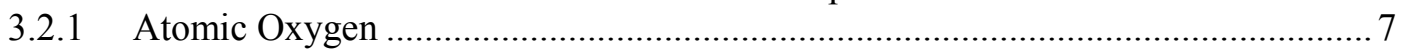

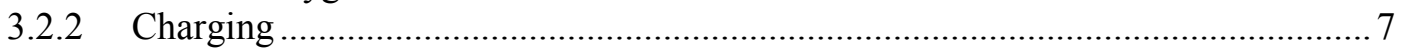

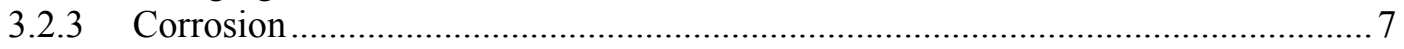

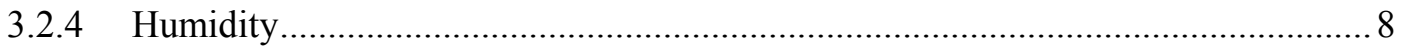

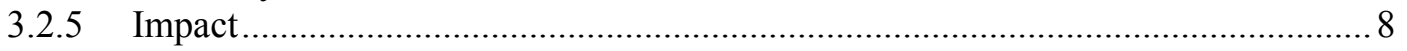

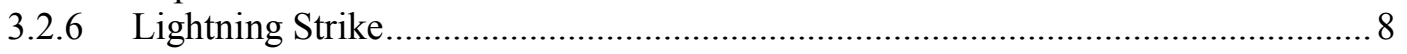

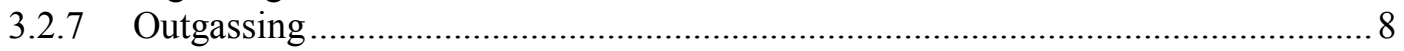

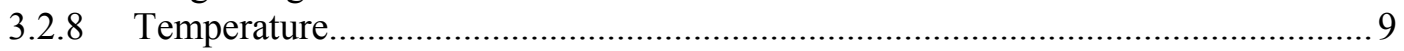

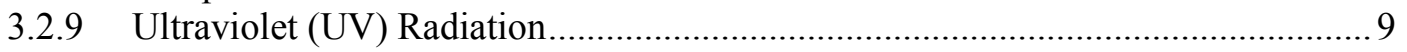

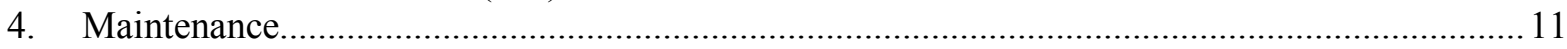

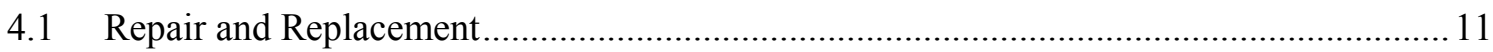

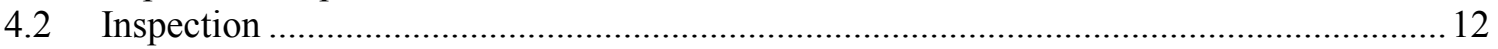

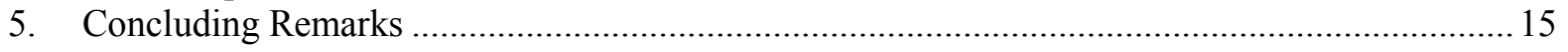

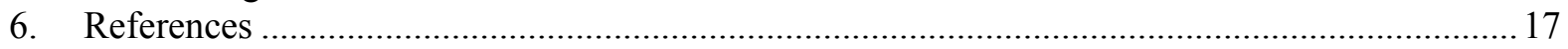

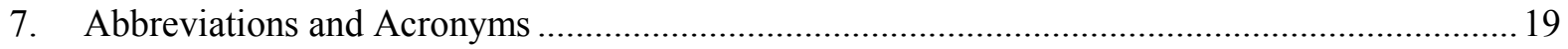

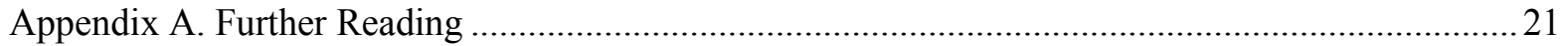




\section{Figures}

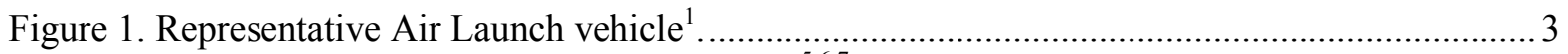

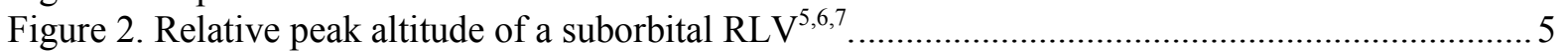

\section{Tables}

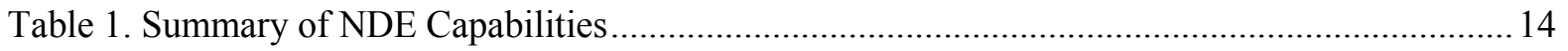




\section{Introduction}

Composites have been used in aircraft construction since the 1950s and are currently used in general aviation and amateur-built aircraft as well as in large transport category aircraft. In fact, the composite mass fraction for primary structure is increasing to improve fuel efficiency. While composites and their characteristics are generally understood in aviation, spacecraft face unique environmental hazards along the flight profile, including extreme temperatures, pressure changes, and atomic oxygen effects. To ensure public safety and, in the future, the safety of both crew and space flight participants, effects of operating in this environment on composites must be well understood. As these vehicles will be designed for repeated exposure to these environments through reuse, they must be properly inspected and maintained. ${ }^{1}$

The objectives of this report are, first, to identify and describe the adverse effects on exposed composites to phenomena associated with environmental spectra traversed by a representative manned suborbital reusable launch vehicle (RLV); and second, to provide insight into maintenance and inspection of composites for RLV applications. The term "environment" refers herein primarily to characteristics of a vehicle's surroundings (e.g., atomic oxygen) that excite an adverse response in composites; it does not address structural loads other than to describe the types of loads that, for composites, require unique attention.

The report begins by proposing a series of candidate RLV flight profiles, and providing a brief description of composite structural materials and their unique sensitivity to fabrication processes and environments. Next, from standards and literature, each of many distinct environments, that an RLV would traverse, are defined. Associated adverse phenomena are identified, and their effects on exposed composites, including mitigation techniques, are given when they are known. The focus is then turned to the subject of maintenance and inspection of composites, for which expertise is drawn from The Aerospace Corporation test laboratories as well as the commercial aviation industry. Finally, a reference listing of articles and standards documents is provided, for further study, as an appendix. 


\section{Candidate RLV Concepts and Composite Construction}

This chapter defines representative configurations and flight profiles for a suborbital RLV. Next, it provides a brief insight to the challenges encountered in using fiber-reinforced polymer matrix composites for aerospace vehicles when designed for atmospheric and space environments.

\subsection{Flight Profiles}

The type of RLV considered in this document is assumed to share general characteristics with four representative vehicle concepts developed for a previous study, one of which is shown in Figure 1. These configurations were developed to closely resemble currently proposed suborbital vehicle concepts, sharing a common apogee of approximately $100 \mathrm{~km}(62 \mathrm{mi})$, and are described here ${ }^{2}$ :

- Horizontal takeoff and landing vehicle with jet engines and rocket engines. This vehicle takes off using jet engines and proceeds to an airborne launch point, where it then climbs to apogee using rocket power and glides to a landing on a runway.

- Ferried and horizontal landing vehicle with rocket engines (referred to as "Air Launch vehicle"). The vehicle is carried aloft by a carrier aircraft to the drop point, where it is released, climbs to apogee using rocket power, and glides to a landing on a runway.

- Horizontal takeoff and landing vehicle with rocket engines. This vehicle takes off using rocket engines, climbs to apogee using rocket power, and glides to a landing on a runway.

- Vertical takeoff and landing vehicle with rocket engines. This vehicle takes off vertically using rocket engines, coasts to apogee, and lands by rocket-powered descent.
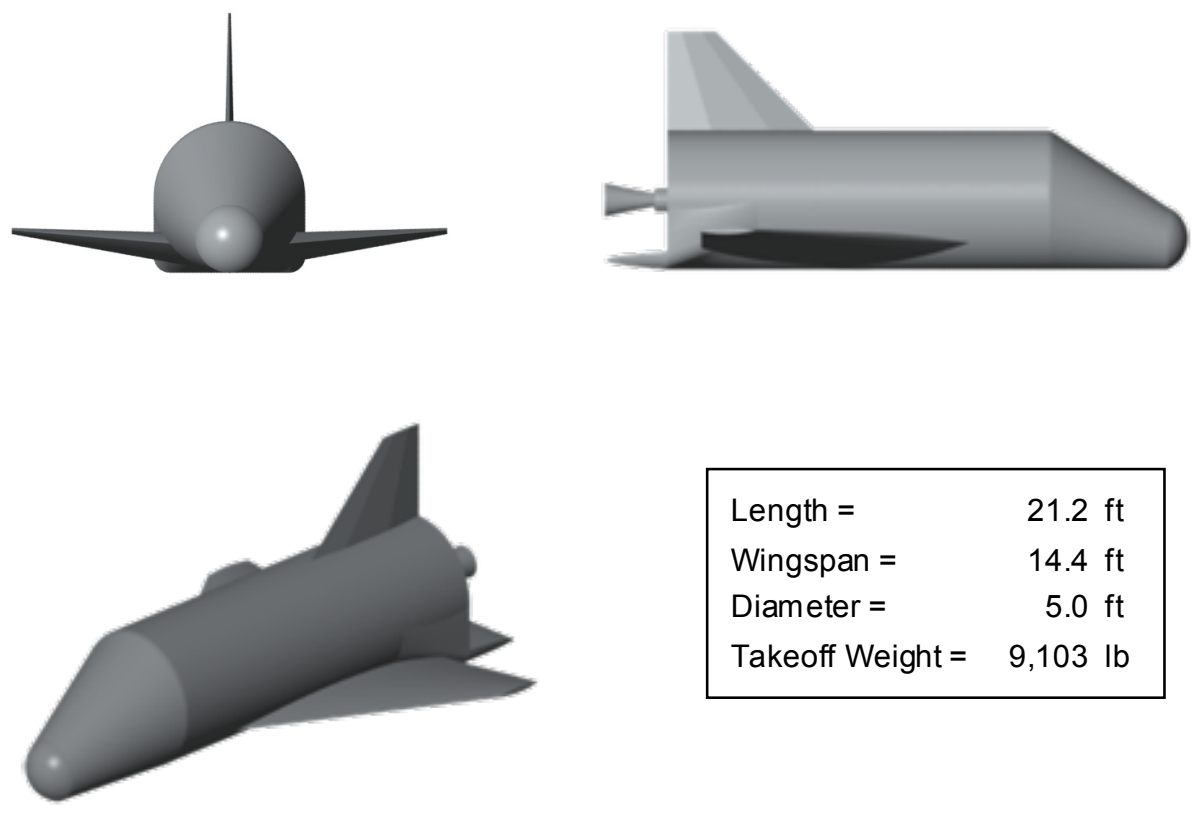

\begin{tabular}{lr}
\hline Length = & $21.2 \mathrm{ft}$ \\
Wingspan $=$ & $14.4 \mathrm{ft}$ \\
Diameter $=$ & $5.0 \mathrm{ft}$ \\
Takeoff Weight $=$ & $9,103 \mathrm{lb}$ \\
\hline
\end{tabular}

Figure 1. Representative Air Launch vehicle ${ }^{1}$. 


\subsection{Composite Structure}

This document considers the effects of the operational environment on, and maintenance of, exposed composite structure. The review is centered on a fiber-reinforced polymer matrix composite system, the use of which is a key enabler of structurally-efficient and therefore affordable RLVs; exotic systems such as ceramic- and metal-matrix composites are not considered. ${ }^{3,4}$ Adhesives are included when appropriate, because they may be used to join composite structures, and are also susceptible to certain limitations in common with composites, such as operational temperatures and dissimilar thermal expansion coefficients to those of adjacent materials.

Performance of composites materials exhibits direct sensitivity to manufacturing processes. Some effects may be subtle, including those attributed to ambient conditions (e.g., humidity and temperature), and whether specified cure cycle ramp rates and holds (e.g., temperature and duration) are achieved. Examples of obvious detrimental manufacturing errors include trapping debris between plies during layup; in the case of honeycomb-core sandwich structure, insufficient population of expanding foam adhesive along core splices leads to local loss of shear stiffness and load capacity. Also, damage to a cured composite structure may occur during removal of a part from its tool during trim operations or assembly.

Likewise, composites exhibit sensitivity to certain operational environments and loads. Environments to consider include moisture, extreme temperatures, and potentials due to charging, among several others. Loading concerns include delamination due to load convention (composite laminates exhibit low tolerance to out-of-plane loads), impact, and the effect of coefficient of thermal expansion mismatch (e.g., ply-wise and also with mating structure) when subjected to thermal loads. This brief description provides limited insight to the issues unique to composites for aerospace structures. The Composite Materials Handbook, CMH-17, (formerly MIL-HDBK-17) gives a thorough treatment of composite material systems ${ }^{19}$. 


\section{Operational Environments and Their Effects on Composites}

This chapter describes the spectrum of environments to which a composite suborbital RLV will be subjected, and identifies phenomena that may have an adverse effect on composites and adhesives. It also provides insight to mitigation methods when they are known. The effects are organized by environmental phenomena.

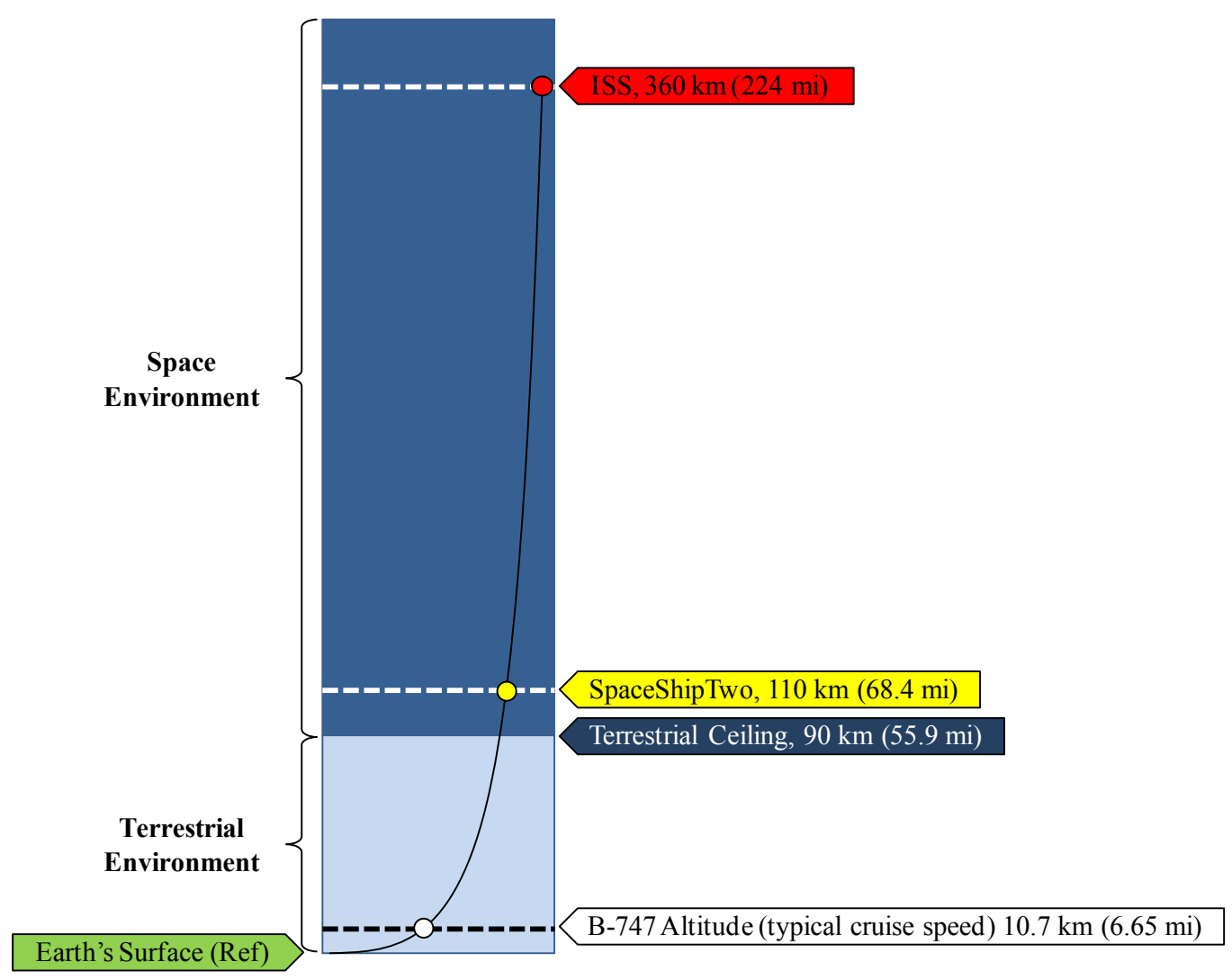

Figure 2. Relative peak altitude of a suborbital $\operatorname{RLV}^{5,6,7}$.

\subsection{Operational Environments}

The operational environment of a suborbital RLV spans ground operations to the space environment, including exposure to the terrestrial flight regime on both ascent and reentry/descent. For perspective, the relative peak altitude of a composite suborbital RLV (Scaled Composites and Virgin Galactic's in-development SpaceShipTwo), a B-747's cruise altitude, and an averaged (apogee and perigee) orbital height of the International Space Station (ISS) are illustrated in Figure $2^{5,6,7}$ Aerospace structures constructed of fiber-reinforced polymer matrix composite systems, including paste and film adhesives used to join such structures, must be suited for the effects due to phenomena found in each environment. Examples are loss of polymer matrix at external leading surfaces, called ram surfaces, due to exposure to atomic oxygen; sensitivity of composites to operating temperatures; and potential for polymeric materials to exhibit outgassing behavior ${ }^{8}$. 


\subsubsection{Ground Environment}

The ground environment poses numerous threats to a composite RLV. In fact, the ground environment has been identified as a central source of damage in the military realm, due to damage that occurs during maintenance ${ }^{9}$, and it is common for designers to fail to account for ground-based events, leading to damage that may go unnoticed ${ }^{10}$. Threats on the ground may include uncontrolled storage temperature, extended exposure to inclement weather during unscheduled halts while awaiting takeoff, emergency procedures upon roll-out after landing, and self-powered or assisted taxiing. In addition, RLVs may be exposed to contaminants from adjacent flight- and servicevehicles, including debris common to runways. A similar threat is posed by equipment and toolwielding personnel, foreign object debris (FOD) (e.g., solid or fluid contaminants inadvertently trapped between composite plies or bond surfaces during maintenance), and chemicals.

Transportation, handling, and storage of RLVs and their structural components, for instance, spares, or routine replacements, should be performed with care. Measures may include attaching handling fixtures when transporting unmated components to protect and stabilize otherwise unsupported structure from unaccounted loads. While exposure to adverse environmental sources like extreme temperatures should be avoided, unanticipated events may occur, and a means should be in place to record and maintain a history of such events and procedures used. Appropriate recording devices, written accounts, and photographs should be required to provide useful documentation when assessing a component's subsequent structural integrity ${ }^{8}$. Phenomena, and their adverse effects, which may occur both on the ground and in flight (e.g., hail, extreme temperatures) are discussed in greater detail in the upcoming sections on terrestrial and space flight environments.

\subsubsection{Terrestrial Flight Environment}

All spacecraft traverse the terrestrial environment, which has a ceiling of approximately $90 \mathrm{~km}$. Manned spacecraft (e.g., ISS modules) are shielded by launch-vehicle shrouds, or stowed within the space shuttle bay during this portion of the flight, whereas time spent in the terrestrial environment comprises a significant portion of manned suborbital RLV flight profiles. Therefore, the suborbital RLV must be designed with an understanding of dangers posed not only by space, but also by the terrestrial environment. While the terrestrial environment includes several phenomena and mitigation philosophies beyond those discussed herein (e.g., navigation philosophy for inclement weather and ingestion of foreign objects), the focus of this report is to identify those that may excite adverse structural response in composite laminates. Mission design should consider severe inclement weather, such as powerful storms using terrestrial environment data. An RLV will, regardless, be subjected to associated elements, like moisture (e.g., cloud penetration, rain, and humidity), hail, and lightning strike, which can have adverse effects unique to exposed composite structures ${ }^{11}$.

\subsubsection{Space Flight Environment}

Though suborbital RLVs will spend a considerable portion of their flight profiles within the atmospheric flight regime, proposed concepts are anticipated to feature maximum altitudes that extend $20 \mathrm{~km}(12.4 \mathrm{mi})$ into the space environment. It is therefore necessary to identify and understand the adverse effects due to exposure to phenomena such as atomized oxygen molecules, radiation, and micrometeoroids in the design and upkeep of composite surfaces. 


\subsection{Environmental Phenomena and Their Effects on Composites}

Certain elements of operational environments pose concerns to the integrity of composite aerospace structures. Phenomena are identified and described, with the emphasis being on the threat to composites. Some are unique to the space environment (e.g., atomic oxygen), while others (e.g., hygroscopic effects) originate from exposure in the terrestrial manufacturing and operational environment but may manifest themselves in the space environment. Finally, there are phenomena, like impact due to hail or micrometeoroid particles, which are present in both environments. The opportunity for more frequent inspection of RLVs, relative to spacecraft like satellites, may perhaps provide greater tolerance for certain phenomena, such as corrosion.

Environment exposure models have not kept pace with improving understanding of the adverse effects of phenomena ${ }^{12}$, like matrix cracking due to thermal cycling and micrometeoroid impact, synergistic effects of which have been shown more degrading than when acting independently ${ }^{13}$. Since a suborbital RLV will experience brief but repeated exposure to the space atmosphere, greater understanding should be attained of the effect of exposure levels, and also of potential effects due to periodic alternating exposure to the atmospheric and space environments.

\subsubsection{Atomic Oxygen}

Atomic oxygen, present at lower altitudes, occurs when diatomic oxygen molecules are split apart but fail to reform. It is chemically reactive and can erode exposed surfaces. Its effect is typically limited to ram surfaces, though NASA's Long Duration Exposure Facility (LDEF) mission reported degradation of a trailing-edge sample. Polymeric materials, like a composite's matrix, can be susceptible to this phenomenon, and layup architecture has been identified to play a significant role in severity. Thin metallic or oxide coatings serve as mitigation ${ }^{14,15,16,25}$. If adhesively bonded joints are used to join composite structure, then precautions may be necessary to protect exposed bond lines and stress-reducing spew fillets.

\subsubsection{Charging}

The upper atmosphere, at altitudes beyond $90 \mathrm{~km}$ (55.9 mi), contains charged particles, which may, in addition to influencing electronic equipment, also charge the composite surfaces of space vehicles to levels that can cause accelerated erosion by virtue of ion sputtering. Vehicles may develop a charge relative to its surroundings, or a differential charge, the latter referring to a potential between the vehicle's components. Sufficient conditions may elevate fields to levels that may approach the material's breakdown strength ${ }^{17,18}$. Differential charging may be addressed by the use of conductive or partially-conductive materials or coatings at exposed surfaces, which should be grounded to the spacecraft's structure. $^{25}$

\subsubsection{Corrosion}

Care should be taken when certain carbon composites are integrated with metallic materials such as aluminum and steel (e.g., a thin metallic sheet within a laminate for fastener bearing purposes) because of the likelihood of galvanic corrosion. Intermediate fiberglass plies can prevent this. A composite's polymer matrix exhibits a deleterious response to chemicals like paint strippers, and therefore their use is not recommended ${ }^{19}$. 


\subsubsection{Humidity}

Polymeric matrix materials tend to absorb moisture, the presence of which may be due to humidity, precipitation, or possibly cloud penetration. While potentially reversible, and while the phenomenon causes internal strains to develop, the presence of moisture causes a decrease in the matrix material's glass transition temperature. The potential for a synergistic effect with elevated operational temperatures should be considered ${ }^{19}$. Conversely, any consequences of moisture-starvation, due to operations in arid climates, may also require consideration. A controlled environment may provide mitigation during the manufacturing process and also during storage. The practice of venting sandwich core materials for use in space to accommodate changes in pressure may lead to moisture ingestion. Selection of resin may contribute to in-service performance; cyanate ester resins and semicrystalline thermoplastics are less hygroscopic (i.e., less likely to absorb moisture) than epoxies, though influence of the length of exposure should be characterized ${ }^{30}$. Coatings may offer protection, in parallel, against other phenomena.

\subsubsection{Impact}

Composites, due to the relatively brittle matrix material and low, out-of-plane, interlaminate strengths, are sensitive to impact damage, which can lead to unnoticeable local delamination and/or fiber breakage, which can suddenly and substantially reduce a laminate's structural properties ${ }^{20}$.

The storage, maintenance, and operational environments of suborbital RLV structures will expose them to several forms of impact damage. A few intuitively carry over from the aviation realm. They include inadvertent contact with tools, maintenance equipment, rain, hail, and bird strike. The space environment introduces additional opportunities for impact damage due, for example, to high relative speeds of micrometeoroids or dust particles striking leading surfaces. The latter may be better regarded as a surface wear issue for which mitigating measures such as rain erosion coats and paints should be considered ${ }^{8,19}$. In aviation, paints used on composite structure have exhibited cracking and chipping within a few years of application. The phenomenon is not yet understood; it may be speculatively attributed to the mismatch between the coefficient of thermal expansion of the paint, and that of the composite substrate, or to unreacted resin degrading the paint ${ }^{31}$.

\subsubsection{Lightning Strike}

Lightning poses risks to exposed composite structure; internal structure may also be subjected to damage when its fasteners are shared with exposed structure. Such common fasteners should be interconnected by conducting wire and grounded, while conductive surfaces are recommended as protection for exposed surfaces ${ }^{19}$. Susceptibility of composite structure to damage and serviceinterruption resulting from lightning strike is substantiated by reports from commercial aviation carriers of heat damage and large debonds on composite rudders, outboard ailerons, and engine cowls; corresponding repair procedures for even localized damage may span several days ${ }^{21,22}$.

\subsubsection{Outgassing}

Outgassing is not anticipated to be a driving concern for suborbital RLVs, but is understood to influence the dimensional stability of a composite's matrix and also adhesives ${ }^{23,24}$. This may be of concern for structural regions where dimensional tolerances are critical, for example joints ${ }^{25}$. 
Consideration should also be given to sandwich structure components such as core materials (e.g., closed or open-cell foam, and honeycomb).

\subsubsection{Temperature}

Coefficient of Thermal Expansion (CTE) Mismatch. The disparity between the coefficients of thermal expansion between laminates and adhesives should be considered if adhesively bonded joints are used to join composite structures because of the likelihood of strain developing due to differences in CTE between the adhesive and the composite system ${ }^{23}$. The severity of this should be investigated to determine whether the driving effect is at elevated or low temperature extremes (i.e., atmospheric or space environment).

Temperature Extremes. Composite materials exhibit sensitivity to service temperature due to the adverse effect on the matrix materials stiffness and strength. The operational temperature range should be understood (including contingency operations ${ }^{8}$ ), and a margin should exist between the glass transition temperature and the operational temperature for the matrix material to maintain stiffness and strength. It has been postulated that a margin greater than $28^{\circ} \mathrm{C}\left(50^{\circ} \mathrm{F}\right)$ be maintained ${ }^{19}$. The same holds for adhesives used for bonded joint applications. Extreme low temperatures can lead to brittle failure of some polymeric materials, while bond strengths degrade at extreme elevated temperatures ${ }^{16}$.

Thermal Cycling. Composite materials exhibit orthotropic response to changes in temperature, which is an artifact of the difference in CTE between the matrix and fiber materials and the orientation of fibers in a laminate. The matrix drives the response in a unidirectional laminate in the direction normal to the fiber reinforcement, while the response in the fiber reinforced direction is dominated by the fibers, and may be negligible. The characteristics of woven (e.g., bidirectional fabrics) composites should be considered. While this property may provide design capabilities, it can cause matrix microcracking in composites subjected to thermal cycling. In cross-ply laminates, this has been shown to introduce hysteresis effects, effect significant changes in net CTE, and elevate hygroscopy. Toughened epoxy systems have been demonstrated to be resistant to microcracking ${ }^{25}$. The cyclic loads due to thermal changes must be accounted for in assessments of fatigue life.

\subsubsection{Ultraviolet (UV) Radiation}

If polymer materials are used for structural applications like adhesives in bonded joint applications and epoxy resins in composite systems, it may be necessary to investigate the influence of UV radiation, which LDEF experiments demonstrated may, over time, significantly reduce the strength of such materials ${ }^{16,19,25}$. 


\section{Maintenance}

This chapter provides insight to the maintainability of composite structure. Challenges associated with repair of composite structure are described, and a design-for-maintenance philosophy is highlighted. The need for inspection is described, and insight is provided on suitability of various inspection techniques.

\subsection{Repair and Replacement}

Periodic and unscheduled maintenance are necessary to maintain composites used on RLVs. Proper planning for maintenance of composites has been identified as a significant component in reducing cost, and generic processes are sought by repair depots ${ }^{9}$. A support plan that accounts for available inspection and repair techniques before and after delivery should be developed in parallel with design activities. A thoughtful plan will contribute to correct and timely maintenance procedures, which will benefit composite structures demonstrated to be highly sensitive to processes and also responsive to environments. The nature of composite designs, which exhibit directionality and may feature characteristics like complex curvature and unique jointing schemes to achieve increased structural efficiency, is a detriment to their maintainability ${ }^{26,27,28}$. Since RLVs and aircraft operate in two common environments (e.g., ground and atmospheric flight), certain FAA Federal Aviation Regulations (FARs), Airworthiness Directives, and Advisory Circulars may be adapted, but due to the FARs' implementation and architecture, they should be judiciously applied after appropriate tailoring ${ }^{29}$.

A composite structural component, once mated using mechanical or adhesive joints, or integrally (e.g., via co-bonding, co-curing, or stitching), may require maintenance. Only the mechanical joint may be disassembled without requiring considerable touch labor, in addition to possible initiation of damage to adjacent structure. One maintenance approach is to do so, substituting a replacement or interchangeable piece, the distinction being that replacements are acknowledged to require local modification such as trimming, or shimming. The alternative is to design or implement a standardized repair; a contingency that should be considered by the designer ${ }^{27}$. Repair activities must follow approved processes, after which flightworthiness must be demonstrated ${ }^{8}$. Just as composite repairs are highly sensitive to processes, care must be exercised when preparing adhesive bonds ${ }^{10}$.

Coatings can serve to mitigate adverse effects of some operational environments such as providing erosion protection or thermal control. Such coatings should be included in a maintenance plan, as they have demonstrated susceptibility to damage from microscopic particle impact and failure to adhere to substrates when subjected to charged environments ${ }^{12}$. Removal of coatings for maintenance of composites must rely on alternatives to chemical agents, which are known to degrade the composite's matrix, and adjacent coating material ${ }^{27}$.

Just as guidelines for supportability of an RLV's composite structure may benefit from certain practices and lessons learned from aviation, the training sufficiency of migrating and new maintenance staff should be considered ${ }^{29}$. Familiarity with composites and polymeric materials is requisite, because of the high sensitivity of these materials to processes, handling, and environments.

MIL-HDBK-17f Vol. 3 contains lessons learned from several perspectives, including the following, which addresses repair and in-service experience: 
In spite of concerns about the sensitivity of composites to damage, experience in service has been good. Navy aircraft have not experienced any delamination failures in service. Most damage has occurred during assembly or routine service performed on the aircraft.

- Current design, fabrication, and certification procedures adequately prepare the structure to survive its intended environment

Composite components located in the vicinity of engine exhaust are subject to thermal damage. At present there are no acceptable non-destructive inspection (NDI) methods for detecting thermal damage of matrix materials.

- Composite components exposed to engine exhaust or other heat sources should be shielded or insulated to keep temperatures down to an acceptable level

Moisture ingestion is the biggest problem with honeycomb sandwich structure. The thin, stabilized skins that make honeycomb structurally efficient are also the reason they are damage-prone. Panels get walked on and damaged.

- Honeycomb design must be applied judiciously. Repair must account for the possibility of water in the core

Aircraft are commonly painted and repainted. Paint stripping has been done with solvents. Solvents can damage epoxy matrices.

- Increased use of water-based paints and solventless stripping of paint is desirable

Records pertaining to material review board (MRB) actions and in-plant repairs of composite parts should be readily available to personnel responsible for in-service maintenance.

- During routine maintenance checks, depot personnel sometimes find defects or discrepancies. In some cases they have been able to determine that the "defect" was in the part at delivery and considered acceptable

Supportability and repair must be responsive to service environment.

- It is necessary to account for equipment, facilities, and personnel capabilities

\subsection{Inspection}

The need to ensure the health and flightworthiness of RLV structures is a fundamental concern for the success and safety of future commercial space launch ventures. Critical to achieving this are the myriad material- and component-level inspection processes performed throughout the manufacturing, testing, and service life of these flight hardware systems. Among the most vital inspection processes are non-destructive evaluation (NDE) methods used for evaluating the quality of flight structures. NDE methods enable inspection without damaging, sampling, or otherwise sacrificing inspected parts. 
Several NDE techniques are suitable for subassembly inspections; however, options narrow as material systems and subassemblies are integrated and accessibility for inspection becomes limited. Accessibility is particularly relevant to RLV flight structures covered with thermal protection systems (TPSs). Thermal protection systems provide necessary thermal barriers against harsh environments imposed during reentry or by other operational heat loads. As the external skin of the vehicle, TPSs play a crucial role in protecting critical structural elements. The design and capabilities of TPSs vary with location and vulnerability of the underlying structure. Various material systems may be used for TPS, such as ablative or durable insulation coatings, bonded or sprayed multilayers, flexible blankets, or ridged refractory tiles. These protective systems can constrain access to the underlying structures for inspection. In some cases, removal and reapplication of the TPS may be required to inspect these structures. Where direct access to critical flight structures is unavailable or impractical, inspection processes that can penetrate through the TPS are needed.

Specific NDE techniques applicable to inspection of RLVs will depend on the type and nature of TPS that may cover the composite structure. A variety of TPS designs are being employed for suborbital RLVs and many become proprietary to RLV developers. TPS designs can range from none at all for systems designed for controlled descent (e.g., by parachute or in the manner of winged aircraft) to relatively thin layers of polymer, cork, foam, or composites for systems designed for rapid descent, with or without power. For example, one material system, MI-15, is a low-density, room-temperaturecuring ablator/insulator, which has been used extensively for thermal protection on aircraft and space launch vehicles. It consists of a filled elastomeric silicone, available in either a sprayable or trowelable form. Another example, MCC-1, is a sprayable cork ablator insulation that replaced MSA2 (Marshall sprayable ablator-2), as TPS on the space shuttle solid rocket boosters. A family of materials designated as low-temperature ablatives (LTAs) typically consists of three ingredients: a resin such as polyester, epoxy, phenolic, bis-malimide, or polyimide; a filler such as cork, microballoons, or silica; and a chopped-fiber reinforcement such as polyamide, glass, silica, quartz, graphite, or boron. Depending on the TPS layer thickness, these protective materials can inhibit detectibility of flaws in the underlying composite structure. While certain NDE techniques can be used with some range of "stand-off" sensitivity (i.e., through the TPS layer), critical inspection may require selected removal and reapplication of the TPS.

Table 1 summarizes a few key features of various NDE techniques and their suitability for inspection of composite structures and TPS-covered RLV systems. Assessments of suitability for this use are based on considerations of conventional application methods for and limitations of each NDE technique.

Additionally, structural health monitoring (SHM) techniques and methodologies may be used. Such techniques make use of continuous or dispersed sensors embedded in laminates, or at judiciously located points throughout a vehicle's structure, to obtain raw acceleration or strain data during operation. Methodologies involving data reduction and subsequent use of results to judge flightworthiness may pose a substantial challenge relative to acquiring the raw data ${ }^{23}$. Insights provided by SHM may be useful during flight-test programs, and also in-service to support inspections and accrue long-term fleet data. 
Table 1. Summary of NDE Capabilities

\begin{tabular}{|c|c|c|c|c|c|c|}
\hline NDE Technique & Coverage & Penetration & $\begin{array}{c}\text { Suitable for } \\
\text { Composites } \\
\text { Y/N }\end{array}$ & $\begin{array}{c}\text { Inspection } \\
\text { beneath } \\
\text { Coatings } \\
\text { Y/N/Ltd }\end{array}$ & $\begin{array}{c}\text { Inspection } \\
\text { through } \\
\text { Stand-Off } \\
\text { Gap } \\
\text { Y/N/Ltd } \\
\end{array}$ & $\begin{array}{l}\text { Suitability } \\
\text { for TPS- } \\
\text { Covered } \\
\text { Structures }\end{array}$ \\
\hline Ultrasound & $\begin{array}{c}\text { Point-to- } \\
\text { point }\end{array}$ & Volume & $\mathrm{Y}$ & Ltd & $\mathrm{N}$ & Low \\
\hline Acoustic emission & Entire part & Volume & Y & Y & Y & $\begin{array}{c}\text { Good } \\
\text { (screening } \\
\text { technique) }\end{array}$ \\
\hline Eddy current & $\begin{array}{c}\text { Point-to- } \\
\text { point }\end{array}$ & $\begin{array}{l}\text { Near } \\
\text { surface }\end{array}$ & $\mathrm{N}$ & $\begin{array}{c}\mathrm{Y} \\
\text { (electrically- } \\
\text { conductive } \\
\text { substrates) }\end{array}$ & Ltd & $\begin{array}{c}\text { Good } \\
\text { (limited TPS } \\
\text { penetration) }\end{array}$ \\
\hline $\begin{array}{c}\text { Electro-magnetic } \\
\text { Acoustic } \\
\text { Transducer } \\
\text { (EMAT) }\end{array}$ & $\begin{array}{l}\text { Point-to- } \\
\text { point }\end{array}$ & Volume & $\mathrm{N}$ & Y & $\mathrm{Y}$ & Good \\
\hline Microwave & $\begin{array}{c}\text { Point-to- } \\
\text { point }\end{array}$ & Volume & Y & $\mathrm{Y}$ & Y & Unknown \\
\hline X-Ray & Full-field & Volume & $\mathrm{Y}$ & $\mathrm{Y}$ & $\mathrm{Y}$ & Good \\
\hline Thermography & Full-Field & Variable & $\mathrm{Y}$ & Ltd & $\mathrm{N}$ & Low \\
\hline
\end{tabular}




\section{Concluding Remarks}

This report provides top-level identification and assessment of the effects of operational environments on composites, their maintainability, and the suitability of various inspection techniques. The identified phenomena are not ranked by severity of the danger each poses to composite structures because such an assessment requires availability and review of substantiated data of sufficiently uniform fidelity and maturity for each identified phenomenon. Noteworthy are the potential for synergistic effects of certain environmentally-induced phenomena, and that for environment coupling, where the effect, due to a phenomenon from one environment, manifests itself in an adverse effect in the other environment. This adds complexity to the prospect of ranking the severity posed by the phenomena. The architecture of such an assessment should be thoughtful. Also, sufficient published data to provide insight into exposure levels or the influence of exposure time to these phenomena at or below the representative suborbital peak altitude was not available, and is desired. Further study, guided by these insights, is recommended. 


\section{References}

1. Seibold, R. W., Statement of Work, DTRT57-05-D-30103 - Task 27B, The Aerospace Corporation, February 2010.

2. Law, G. W., Internal Study, The Aerospace Corporation.

3. Harris, C. E., Starnes, J. H., Shuart, M. J., "Design and Manufacturing of Aerospace Composite Structures, State-of-the-Art Assessment," Journal of Aircraft, vol. 39, pp. 545-560, 2002.

4. Sawyer, J. W., "Graphite-Composite Primary Structure for Reusable Launch Vehicles," AIAA Paper 96-4268, September 1996.

5. Boeing 747 Family, The Boeing Company, http://www.boeing.com/commercial/747family/pf/pf_classics.html, accessed June 2010.

6. Virgin Galactic website, http://www.virgingalactic.com/overview/spaceships/, accessed June 2010.

7. NASA website, ISS Interactive Reference Guide: http:/www.nasa.gov/mission pages/station/main/index.html, accessed June 2010.

8. AIAA Standard S-110-2005, Space Systems - Structures, Structural Components, and Structural Assemblies, July 2005.

9. Larson, P., "USAF Applications of Repair and Supportability of Advanced Composites," FAA Composite Damage Tolerance and Maintenance Workshop.

10. Sarafin, T. P., ed., Spacecraft Structures and Mechanisms: From Concept to Launch, $1^{\text {st }}$ ed., Springer, May 1995.

11. Johnson, D. L., ed., "Terrestrial Environment (Climatic) Criteria Guidelines for Use in Aerospace Vehicle Development,” 2008 Revision, NASA/TM-2008-215633, December 2008.

12. Pippin, H. G., Woll, S. L. B., Blohowiak, K. Y., Olli, L. K., Osborne, J. H., "On-Orbit and Ground Testing of Space Environment Interactions with Materials," Progress in Organic Coatings, vol. 47, pp. 458-468, 2003.

13. Awaja, F., Moon, J. B., Zhang, S., Gilber, M., Kim, C. G., Pigram, P. J., "Surface molecular degradation of 3D glass polymer composite under low earth orbit simulated space environment," Polymer Degradation and Stability, vol. 95, pp. 987-996, 2010.

14. Sellers, J. J., Understanding Space: An Introduction to Astronautics, $2^{\text {nd }}$ ed., Quebecor World, 2004.

15. Larson, W. J., Pranke, L. K., Human Spaceflight: Mission Analysis and Design, McGraw Hill Higher Education.

16. ASTM E 1997-07, ASTM Standard Practice for the Selection of Spacecraft Materials, ASTM International, 2007.

17. Bedingfield, K. L., Leach, R. D., Alexander, M. B., ed., "Spacecraft System Failures and Anomalies Attributed to the Natural Space Environment," NASA Reference Publication 1390, August 1996.

18. Czepiela, S. A., McManus, H., Hastings, D., "Charging of composites in the space environment," Journal of Spacecraft and Rockets, vol. 37, no. 5, pp. 556-560, SeptemberOctober 2000.

19. U. S. Department of Defense, Washington D. C., Military Handbook: Composite Materials Handbook, vol. 3f., chap. 12, 2002.

20. U. S. Department of Defense, Washington D. C., Military Handbook: Composite Materials Handbook, vol. 3f., chap. 7, 2002.

21. Yamanaka, J., "JAL Perspective on Application \& Field Experiences for Composite Structure," $3^{\text {rd }}$ FAA/EASA/Industry Composite Damage Tolerance and Maintenance Workshop, June 2009. 
22. Chesmar, E., "United Airlines Maintenance Experience: Context, Past Issues, and Trends," FAA Composite Damage Tolerance and Maintenance Workshop, July 2006.

23. Nokes, J., Interview, The Aerospace Corporation, (April 2010).

24. Giants, T. W., Correspondence, The Aerospace Corporation, June 2010.

25. Silverman, E. M., "Space Environmental Effects on Spacecraft: LEO Materials Selection Guide," NASA Contractor Report 4661, Part 1, August 1995.

26. Federal Aviation Administration, Washington D. C., Guide to Commercial Reusable Launch Vehicle Operations and Maintenance, version 1, March 2005.

27. U. S. Department of Defense, Washington D. C., Military Handbook: Composite Materials Handbook, vol. 3f., chap. 8, 2002.

28. National Aeronautics and Space Administration, Langley Research Center, Hampton, VA, NASA Standard Procedure: Advanced Composite Structures, NASA SP 8108, December 1974.

29. Larsen, C. R., "Commercial Space Transportation Reusable Launch Vehicle Operations \& Maintenance Developments," Space 2003, AIAA Paper 2003-6407, 2003.

30. U. S. Department of Defense, Washington D. C., Military Handbook: Composite Materials Handbook, vol. 3f., chap. 2, 2002.

31. Sauer, C., "Lufthansa Perspective on Applications \& Field Experience for Composite Airframe Structures," FAA Workshop, Chart Package, November 2007. 


\section{Abbreviations and Acronyms}

$\begin{array}{ll}\text { AIAA } & \text { American Institute of Aeronautics and Astronautics } \\ \text { AO } & \text { Atomic Oxygen } \\ \text { AST } & \text { Office of Commercial Space Transportation } \\ \text { ASTM } & \text { American Society of Testing and Materials } \\ \text { COTR } & \text { Contracting Officer's Technical Representative } \\ \text { CTE } & \text { Coefficient of Thermal Expansion } \\ \text { FAA } & \text { Federal Aviation Administration } \\ \text { FOD } & \text { Foreign Object Debris } \\ \text { ISS } & \text { International Space Station } \\ \text { LDEF } & \text { Long Duration Exposure Facility } \\ \text { NASA } & \text { National Aeronautics and Space Administration } \\ \text { NDE } & \text { Non-Destructive Evaluation } \\ \text { NDI } & \text { Non-Destructive Inspection } \\ \text { MIL } & \text { Military } \\ \text { RLV } & \text { Reusable Launch Vehicle } \\ \text { SHM } & \text { Structural Health Monitoring } \\ \text { SP } & \text { Standard Procedure } \\ \text { SS2 } & \text { SpaceShipTwo } \\ \text { TPS } & \text { Thermal Protection System } \\ \text { UV } & \text { Ultraviolet }\end{array}$




\section{Appendix A. Further Reading}

1. Abbott, R., "Load Enhancement Factor for Composite Spectra (Raytheon Method)," FAA Workshop, Chart Package, July 2006.

2. Anderson, B. J. (ed.), and Smith, R. E. (compiled), "Natural Orbital Environment Guidelines for Use in Aerospace Vehicle Development," NASA TM 4527, June 1994.

3. Behrens, B., Müller, M., "Technologies for Thermal Protection Systems Applied on Re-Usable Launcher," Acta Astronautica, vol. 55, pp. 529-536, 2004.

4. Bensoussan, D., "Space Tourism Risks: A Space Insurance Perspective," Acta Astronautica, vol. 66, pp. 1633-1638, 2010.

5. Berner, J., "Bolted Repair in Composite Structure: 787 Wing/Empennage/Landing Gear," FAA Workshop, Chart Package, June 2009.

6. Brey, P., Timmerman, T., Rokala, A., "Staying Ahead of the Game: Keeping a Composite Airplane Fleet Airworthy," FAA Workshop.

7. Chudoba, B., Huang, X., Coleman, G., and Czysz, P. A., "Future Space Tourism Transportation Design Requirements," AIAA Paper 2005-3445, 2005.

8. Coleman, G., Chudoba, B., and Huang, X., "Assessment of Current Space Access Vehicle Tourism Regulations and Their Implications on Design,” AIAA Paper 2006-1528, January 2006.

9. Daniel, L., Tumino, G., Henriksen, T., and Dujarric, C., "Advanced Composite Technology in Reusable Launch Vehicle (RLV),” AIAA Paper 2004-5825, San Diego, CA, September 2004.

10. de León, P., Williamson, M. R., "A Full-Pressure Space Suit with Bailout Capabilities for Experimental Suborbital Vehicles," Acta Astronautica, vol. 60, pp 497-504, December 2006.

11. Department of the Air Force DOD-HDBK-343, "Design, Construction, and Testing Requirements for One of a Kind Space Equipment," February 1986.

12. Esquivel, O., and Kim, Y. M., "Quantitative Evaluation of Flaw-Detection Limits of Eddy Current Techniques for Interrogating Structures Beneath Thermal Protection Systems on Reusable Launch Vehicles," Aerospace Report No. ATR-2005(5131)-1, February 2005.

13. Esquivel, O., and Seibold, R. W., "Capabilities and Limitations of Nondestructive Evaluation Methods for Inspecting Components Beneath Thermal Protection Systems," Aerospace Report No. ATR-2004(5081)-1, July 2004.

14. Fawcett, A. J., Oakes, G. D., "Boeing Composite Airframe Damage Tolerance and Service Experience," FAA Workshop.

15. Fayazbakhsh, K., Abedian, A., "Materials Selection for Applications in Space Environment Considering Outgassing Phenomenon," Advances in Space Research, vol. 45, pp. 741-749, 2010.

16. Freeman, D. C., Talay, T. A., and Austin, R. E., "Single-Stage-to-Orbit - Meeting the Challenge," Acta Astronautica, vol. 38, pp. 323-331, 1996.

17. Freeman, D. C., Talay, T. A., and Austin, R. E., "Reusable Launch Vehicle Technology Program," Acta Astronautica, vol. 41, pp. 777-790, 1997.

18. Galella, D., "FAA Inspection Research Activities for Composite Materials," FAA Composite Damage Tolerance \& Maintenance Workshop, Chart Package, July 2006.

19. Gates, T. S., Su, X., Abdi, F., Odegard, G. M., Herring, H. M., "Facesheet Delamination of Composite Sandwich Materials at Cryogenic Temperatures," Composite Science and Technology, vol. 66, pp. 2423-2435, 2006.

20. Grossman, E., Gouzman, I., "Space Environment Effects on Polymers in Low Earth Orbit," Nuclear Instruments and Methods in Physics Research B, vol. 208, pp. 48-57, 2003. 
21. Guida, M., Marulo, F., Polito, T., Meo, M., and Riccio, M., "Design and Testing of a FiberMetal-Laminate Bird-Strike-Resistant Leading Edge," Journal of Aircraft, vol. 46, November 2009.

22. Harris, C. E., Starnes, J. H., and Shuart, M. J., "Design and Manufacturing of Aerospace Composite Structures, State-of-the-Art Assessment," Journal of Aircraft, vol. 39, July 2002.

23. Ilcewicz, L., "Composite Damage Tolerance and Maintenance Safety Issues," FAA Workshop, July 2006.

24. Ilcewicz, L., Cheng, L, Hafenricher, J., and Seaton, C., U. S. Department of Transportation, Federal Aviation Administration DOT/FAA/AR-08/54, "Guidelines for the Development of a Critical Composite Maintenance and Repair Issues Awareness Course," February 2009.

25. Jones, R., and Smith, W. R., "Continued Airworthiness of Composite Repairs to Primary Structures for Military Aircraft,” Composite Structures, vol. 33, pp. 17-26, 1995.

26. Kim, H., and Halpin, J., "Managing Damage Threats for Composite Structures: Unifying Durability and Damage Tolerance Perspective," FAA/EASA Meeting, June 2009.

27. Kleiman, J. I., Iskanderova, Z. A., Pérez, F. J., and Tennyson, R. C., "Protective Coatings for LEO Environments in Spacecraft Applications," Surface Coatings and Technology, 1995.

28. Lamontagne, C. G., Manuelpillai, G. N., Kerr, J. H., Taylor, E. A., Tennyson, R. C., and Burchell, M. J., "Projectile Density, Impact Angle, and Energy Effects on Hypervelocity Impact Damage to Carbon Fibre/PEEK Composites," Int. Journal of Impact Engineering, vol. 26, pp 381-398, 2001.

29. Massobrio, F., Viotto, R., Serpico, M., Sansone, A., Caporicci, M., and Muylaert, J. M., "EXPERT: An Atmospheric Re-Entry Test-Bed," Acta Astronautica, vol. 60, pp. 974-985, 2007.

30. Mohaghegh, M., "Evolution of Structures Design Philosophy and Criteria," Journal of Aircraft, vol. 42, July 2005.

31. MSFC-RQMT-3479, "Fracture Control Requirements for Composite and Bonded Vehicle and Payload Structures," National Aeronautics and Space Administration, 2006.

32. Public Lessons Learned Entry 0735, "Material Selection Practices," Marshall Space Flight Center, National Aeronautics and Space Administration, April 2000.

33. NASA-HDBK-4002, "Avoiding Problems Caused by Spacecraft On-Orbit Internal Charging Effects," NASA Technical Handbook, National Aeronautics and Space Administration, February 1999.

34. NASA-STD-4005, "Low Earth Orbit Spacecraft Charging Design Standard," National Aeronautics and Space Administration, June 2007.

35. NASA-HDBK-4006, "Low Earth Orbit Spacecraft Charging Design Handbook," National Aeronautics and Space Administration, June 2007.

36. NASA-STD-6016, "Standard Materials and Processes Requirements for Spacecraft," National Aeronautics and Space Administration, July 2008.

37. NASA-STD-8729.1, "Planning, Developing, and Managing and Effective Reliability and Maintainability (R\&M) Program," National Aeronautics and Space Administration, December 1998.

38. Quine, B. M., Seth, R. K., Zhu, Z. H., "A Free-Standing Space Elevator Structure: A Practical Alternative to the Space Tether," Acta Astronautica, vol. 65, pp. 365-375, 2009.

39. Raju, I. S., "NASA Langley Damage Tolerance Experiences (NASA Engineering and Safety Center)," FAA Symposium on Composite Damage Tolerance and Maintenance, Chicago, July 2006. 
40. Ransom, J. B., Glaessgen, E. H., Raju, I. S., Harris, C. E., "Recent Advances in Durability and Damage Tolerance Methodology at NASA Langley Research Center," AIAA Paper 2007-2377, Honolulu, HI, April 2007.

41. Rapp, B., "Materials for Extreme Environments," Materials Today, vol. 9, no. 5, pp. 6-7, May 2006.

42. Schonberg, W. P., "Protecting Earth-Orbiting Spacecraft Against Micro-Meteoroid/Orbital Debris Impact Damage Using Composite Structural Systems and Materials: An Overview," Advances in Space Research, vol. 45, pp. 709-720, 2010.

43. Seneviratne, W. P., Tomblin, J. S., "Durability \& Damage Tolerance Testing and Analysis Protocols for Composite Structures: Life Factor, Load-Enhancement Factors, and Fatigue Life," FAA/EASA/Industry Composite Damage Tolerance \& Maintenance Workshop, Chart Package, Tokyo, Japan, June 2009.

44. Shyprykevich, P., "FAA R\&D in Composite Sandwich Structures," FAA Damage Tolerance \& Maintenance Workshop, July 2006.

45. Silverman, E. M., "Space Environmental Effects on Spacecraft: LEO Materials Selection Guide," NASA CR 4661 Part 1, August 1995.

46. Silverman, E. M., "Space Environmental Effects on Spacecraft: LEO Materials Selection Guide," NASA CR 4661 Part 2, August 1995.

47. Soderquist, J. R., "Damage Tolerant Considerations in Composite Aircraft Structure," FAA Workshop, Chart Package.

48. Stickler, P., "Composite Materials for Commercial Transport - Issues and Future Research Direction," Technical Paper, ASC $17^{\text {th }}$ Annual Technical Conference.

49. Tenney, D. R., Davis, J. G., Jr., Pipes, R. B., and Johnston, N., "NASA Composite Materials Development: Lessons Learned and Future Challenges," 2009.

50. Tomblin, J. S., Seneviratne, W., "FAA Research on Large-Scale Test Substantiation," FAA Damage Tolerance and Maintenance Workshop, Chart Package, Chicago, IL, July 2006.

51. U. S. Department of Transportation, Federal Aviation Administration, "Repair Stations for Composite and Bonded Aircraft Structure," AC No. 145-6, November 1996.

52. U. S. Department of Transportation, Federal Aviation Administration, "Review of Damage Tolerance for Composite Sandwich Airframe Structures," DOT/FAA/AR-99/49, August 1999.

53. Waite, S., "Damage/Defect Types and Inspection - Some Regulatory Concerns," MIL-17 Maintenance Workshop, Chart Package, Chicago, IL, July 2006.

54. Welch, J. M., "Safe Composite Repairs - Substantiation Linking Repair Test Data to Observed Fleet Performance," FAA Workshop for Composite Damage Tolerance and Maintenance, Chart Package, Chicago, IL, July 2006.

55. Wong, K., "Safety Issues and Considerations Concerning Humans Aboard Commercial Reusable Launch Vehicles,” AIAA Paper 2001-4618, Albuquerque, NM, August 2001.

56. Yamanaka, J., "Japan Airlines Perspective on Application \& Field Experiences for Composite Structure," ${ }^{\text {rd }}$ FAA/EASA/Industry Composite Damage Tolerance and Maintenance Workshop, Chart Package, June 2009.

57. Young, R., "NASA Perspectives on Airframe Structural Substantiation: Past Support and Future Developments," FAA/EASA/Industry Composite Damage Tolerance and Maintenance Workshop, Tokyo, Japan, June 2009. 